\title{
Asymmetrical loading demands associated with vertical jump landings in people with unilateral transtibial amputation
}

\author{
Marlene Schoeman, PhD; ${ }^{1-2^{*}}$ Ceri E. Diss, PhD; ${ }^{1}$ Siobhan C. Strike, $\mathbf{P h D}^{\mathbf{1}}$ \\ ${ }^{1}$ Division of Sport and Exercise Sciences, Department of Human and Life Sciences, University of Roehampton, London, \\ United Kingdom; ${ }^{2}$ Division of Sport and Exercise Medicine, School of Medicine, University of the Free State, Bloemfontein, \\ South Africa
}

\begin{abstract}
Loading symmetry during vertical jump landings between a person with amputation's intact and prosthetic limbs was assessed to determine the role of each limb in controlling the downward momentum of the center of mass during landing. Six participants with unilateral transtibial amputation (TTA) and ten nondisabled participants completed 10 maximal vertical jumps, of which the highest jump was analyzed. Contralateral symmetry was assessed through the Symmetry Index (SI), while symmetry at the group level was assessed through a Mann-Whitney U test. Participants with TTA performed quasiunilateral landings onto the intact limbs, resulting from either the incapability of the prosthetic ankle to plantar flex or increased residual-limb knee and hip flexion. In the loading phase, the participants with TTA displayed reduced prostheticside peak vertical forces $(p=0.04)$ along with reduced prosthetic-side ankle range of motion $(p<0.001)$, extensor moments $(p=0.03)$, and negative work generated $(p=0.00)$. Individual asymmetries were evident in the peak vertical force magnitudes (SI $=51 \%-140 \%)$, duration from touchdown to peak vertical force (SI $=52 \%-157 \%)$, ankle joint angles at touchdown (SI = $100 \%-538 \%$ ), ranges of motion (SI = 147\%-200\%), knee (SI = 66\%-179\%) and hip (SI = 87\%-132\%) extensor moments, and work done at the ankle (SI $=155 \%-199 \%)$ and hip (SI $=83 \%-$ $204 \%)$. High peak forces (25.25 $+/-4.89 \mathrm{~N} \cdot \mathrm{kg}^{-1}$ intact limb and $14.61+/-8.28 \mathrm{~N} \cdot \mathrm{kg}^{-1}$ prosthetic limb) from significantly lower $(p<0.001)$ landing heights than the nondisabled participants indicate a potential injury risk associated with landing for people with TTA.
\end{abstract}

Key words: amputation, asymmetry, biomechanics, exercise, injury prevention, landing mechanics, prosthesis, rehabilitation, shock attenuation, vertical jump.

\section{INTRODUCTION}

People with transtibial amputation (TTA) are encouraged by health professionals to engage in recreational sports for the health and mechanical benefits associated with exercise. Participation in sport not only has a positive influence on people with amputations' self-perception and acceptance of their bodies [1], but exercise also increases longevity and decreases the likelihood of developing various chronic conditions such as hypertension, diabetes, cancer, cardiovascular disease, high cholesterol, obesity, and depression [2], all of which are common problems in sedentary individuals. Inactivity is also a known risk factor for developing osteoporosis due to the associated decrease in mechanical loading to stimulate osteogenesis [3-4]. However, exercise prescription for people with amputation can prove complicated because of conflict between the increased mechanical loading required to

Abbreviations: $\mathrm{CoM}=$ center of mass, $\mathrm{F}_{1}=$ initial peak, $\mathrm{F}_{2}=$ maximum peak, $\mathrm{FH}=$ flight height, $\mathrm{ND}=$ nondisabled, $\mathrm{OA}=$ osteoarthritis, RMSD = root mean square difference, $\mathrm{RoM}=$ range of motion, $\mathrm{SD}=$ standard deviation, $\mathrm{SI}=$ Symmetry Index, TD = touchdown, TTA = transtibial amputation, VGRF = vertical ground reaction force, $\mathrm{VJ}=$ vertical jump.

*Address all correspondence to Marlene Schoeman, PhD; School of Medicine, University of the Free State, Bloemfontein, 9301, South Africa; +27-76-116-4466; fax: +27-86-5766606. Email: schoemanm@ufs.ac.za

http://dx.doi.org/10.1682/JRRD.2012.10.0199 
induce musculoskeletal health and the detrimental effect on articular cartilage when exposed to excessive loading magnitudes or frequencies [5].

Jumping is a fundamental skill in many recreational sports, and inevitably ends in landing. Jump landings carry great potential for stimulating osteogenesis but also carry a high risk of injury due to the associated vertical ground reaction forces (VGRFs) that travel through the human body as a shock wave during collision with the ground [6]. In a typical nondisabled (ND) jump landing, VGRFs show an initial peak $\left(\mathrm{F}_{1}\right)$ shortly after impact [7-8], followed by a maximum peak $\left(\mathrm{F}_{2}\right)$ that is usually representative of the maximum force experienced with eccentric resistance [9]. Since landing impact occurs faster than the response time of the neuromuscular system, the $F_{1}$ magnitude is determined by the preactivation of muscles and kinematic conditions prior to touchdown (TD) [7,10], while the $F_{2}$ magnitude is controlled by voluntary muscle activation [11]. Eccentric plantar flexion slows the lowering of the heel after forefoot contact and reduces the magnitude of $F_{2}$ [8,12-13], ensuring effective control of the downward momentum of the center of mass (CoM). The large range of motion ( $\mathrm{RoM})$ at the intact ankle as the landing progresses, increasing the duration to $\mathrm{F}_{2}$, highlights the shock attenuation role of the ankle. People with TTA must contend with landing forces through a prosthetic ankle that has limited RoM and shock-absorption capabilities. Considering these prosthetic characteristics in combination with an inability to actively produce eccentric force from the severed plantar flexors, it can be expected that the $F_{2}$ magnitude and duration to $F_{2}$ will be affected in people with TTA. High loadings may result in skin breakdown caused by pressures applied by the rigid socket to the residual skin, which cannot tolerate the physiological stress applied to it [14]. Jump landings are commonly associated with musculoskeletal injuries, particularly at the knee when bilateral strength deficits are present [4], and osteoarthritis (OA) over the longer term [5,15-16]. The demands placed on the lower limbs when people with amputation perform dynamic movements with greater impact characteristics are unknown. Previous research has looked at amputation jump takeoff characteristics [17-19] but no research has looked at the landing phase of the jump. Research on unilateral TTA walking and running gait has reported asymmetry where the intact limb experiences a greater loading than the prosthetic limb and/or ND persons [20-22]. People with amputation who are encouraged to participate in physical activity may therefore be compromised because of possible bilateral strength differences and their predisposition to OA at the intact knee and hip [17].

Our primary aim was to assess the asymmetric nature of load acceptance between the intact and prosthetic limbs of active people with TTA during vertical jump (VJ) landings and to explore the role of each limb in accommodating loading and controlling the downward momentum of the CoM to attenuate shock during landing from a maximally executed VJ. Given the bilateral nature of the movement, we hypothesized that the intact and prosthetic $\mathrm{F}_{2}$ magnitudes, joint moments, and joint work would be symmetrical at the group level.

\section{METHODS}

\section{Participants}

Six participants with TTA (5 male and 1 female; age range: 33-49 yr; mass [mean \pm standard deviation (SD)]: $85.33 \pm 13.49 \mathrm{~kg}$; height: $1.86 \pm 0.05 \mathrm{~m}$ ) and $10 \mathrm{ND}$ participants ( 9 male and 1 female; age range: $19-35 \mathrm{yr}$; mass: $80.37 \pm 6.95 \mathrm{~kg}$; height: $1.83 \pm 0.07 \mathrm{~m}$ ) participated in the study. A convenience sample of people with TTA was chosen to enable an analysis of people performing a VJ landing in components they are typically provided with to get a real-life picture of the forces and mechanisms they are experiencing. Participants with TTA were included if they were between the ages of 18 and $50 \mathrm{yr}$ with an amputation at least $1 \mathrm{yr}$ prior to data collection. Participants with TTA were free from pathology secondary to the amputation itself and engaged in recreational activities at least three times per week. The activities engaged in (running, squash, etc.) would not have specifically conditioned the participants with TTA to be proficient jumpers. All participants with TTA wore rigid pylons with their own prescribed prostheses and personal athletic footwear. The magnitude of asymmetry that is deemed normal in jumping is unknown. Therefore, to calculate the tolerance level for the Symmetry Index (SI), ND participants of a similar age range with no pathology who participated in similar recreational activities to the participants with TTA also participated in the study.

\section{Data Collection}

Data were collected in a single session. Following a brisk (self-selected) 5 min treadmill walk, participants were allowed practice VJs prior to data collection. Ten 
maximum-effort bilateral countermovement jumps were performed with each foot on a separate force platform. Participants restricted their arms by placing their hands on their hips to minimize the effect of arm swing on lower-limb mechanics [23], and a 1 min rest between each trial was given. The only instruction given was to "jump as high as possible," without instruction on how to control the landing. Trials were excluded if participants used their arms or missed either force platform during landing, in which case additional trials were collected until 10 acceptable trials were available for analysis.

Data were collected using two force platforms (sample rate: 1,080 Hz) (model 9581C, Kistler AG; Winterhur, Switzerland) synchronized with a nine-camera Vicon motion analysis system (sample rate: $120 \mathrm{~Hz}$ ) (model 612, Oxford Metrics; Oxford, United Kingdom). Thirty-four reflective markers were attached to anatomical landmarks, and anthropometric measurements were taken according to Vicon's requirements for reconstructing the full-body Plug-in-Gait model [24]. On the prosthetic side, marker positions corresponded to those of the intact ankle since it has been shown that the differences in inertial properties between the intact and prosthetic limbs have an insignificant influence on joint moment calculations [25]. The toe and heel markers were placed on the outer surface of the athletic footwear on both the intact and prosthetic sides. The toe markers were placed over the proximal head of the second metatarsal, while the heel marker was placed over the center of the posterior aspect of the calcaneus at the same vertical position as the toe marker. The prosthetic ankle marker was placed directly onto the prosthesis at a vertical position corresponding with the lateral malleolus of the intact side. Joint moments and powers were calculated using standard inverse dynamics procedures [26] using Vicon's Polygon software (Oxford Metrics).

\section{Data Analysis}

All data sets were smoothed using a Woltring crossvalidated quintic spline filtering routine [27] with a $15 \mathrm{~mm}^{2}$ mean squared error noise tolerance. The trial with the greatest vertical position of the CoM was chosen for analysis of the associated landing, since it would result in the highest landing velocity. Flight height (FH) was defined by the CoM displacement from takeoff (VGRF $<10 \mathrm{~N}$ for each respective force platform) while landing was defined from TD (VGRF $>10 \mathrm{~N}$ for each respective force platform) to the point when the CoM reached its lowest point (Figure 1). The duration to $F_{2}$ was measured as the time elapsed from the respective TD to the associated $F_{2}$ peaks.

We analyzed the extent of the asymmetry that resulted from the amputation through the SI and statistical analyses. Responding to the recommendation from previous research, caution was taken not to mask individual landing strategies through an exclusive group analysis [13] because few individuals follow the movement pattern exhibited by group mean data [28]. Also, since different prostheses were worn by the participants with TTA, local bilateral differences for specific discrete measures were assessed through calculation of individual SI values (SI $(\%)=\left[\left(X_{i}-X_{p} \div 0.5\left(X_{i}+X_{p}\right)\right] \times 100\right.$, where $X_{i}=$ variable for the intact limb and $X_{p}=$ corresponding variable for the prosthetic limb). Traditionally, an SI value above 10 percent has been assumed to be asymmetrical. It is not known whether this is reasonable for jumping, and so we analyzed ND performance to determine the expected range of asymmetry. For this research, SI values between 0 and the ND mean SI \pm 1 SD were considered to be functionally symmetrical. Since a limitation of the SI is that the mean of the individual SIs may cancel each other out because of a combination of positive and negative values [29], a Mann-Whitney U test $(p<0.05)$ was used to determine significant differences between the intact and prosthetic limbs for the participants with TTA at the group level. Statistical analyses were conducted using SPSS version 19 (IBM Corporation; Armonk, New York).

The continuous profiles of each data set were explored to investigate whether the findings from the discrete measures were supported by the continuous measure. To compare the difference in profiles between the prosthetic and intact limbs, the root mean square difference (RMSD) was computed from the time when both limbs were in contact with the force platform to the end of landing. The RMSD was normalized as a percentage of the difference between the minimum and maximum values of each profile. Low percentages indicated that the data points throughout landing were similar in value between the two limbs, and therefore, the profiles were similar in shape and magnitude. The normalized RMSD is presented for the ND participants to inform interpretation of the TTA data sets.

All participants performed their maximal VJ; therefore, to determine the role of each limb in accommodating the loading and controlling the downward momentum, the TTA discrete measures were interpreted with respect to the mean ND magnitudes. 
(a)

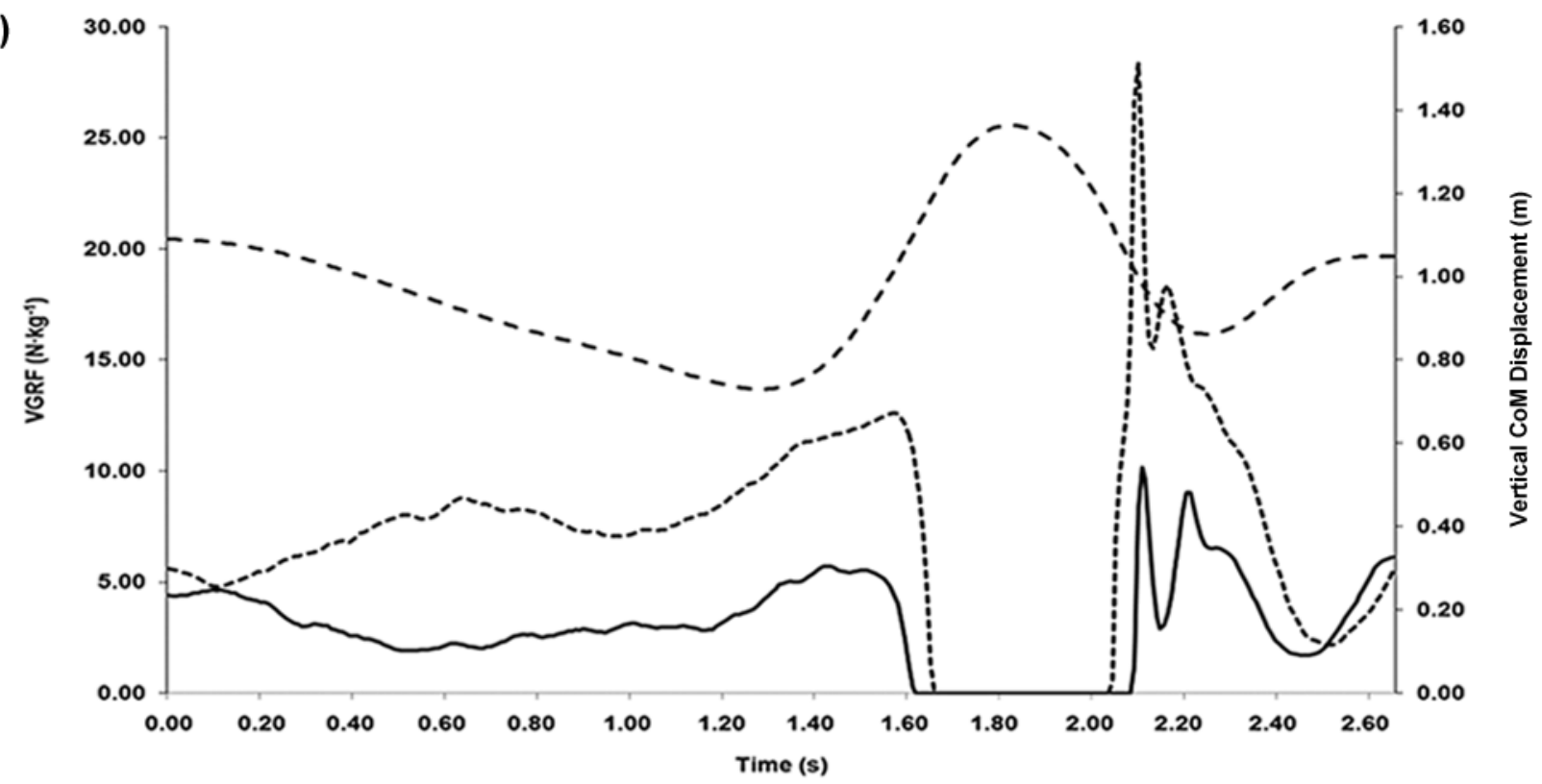

(b)

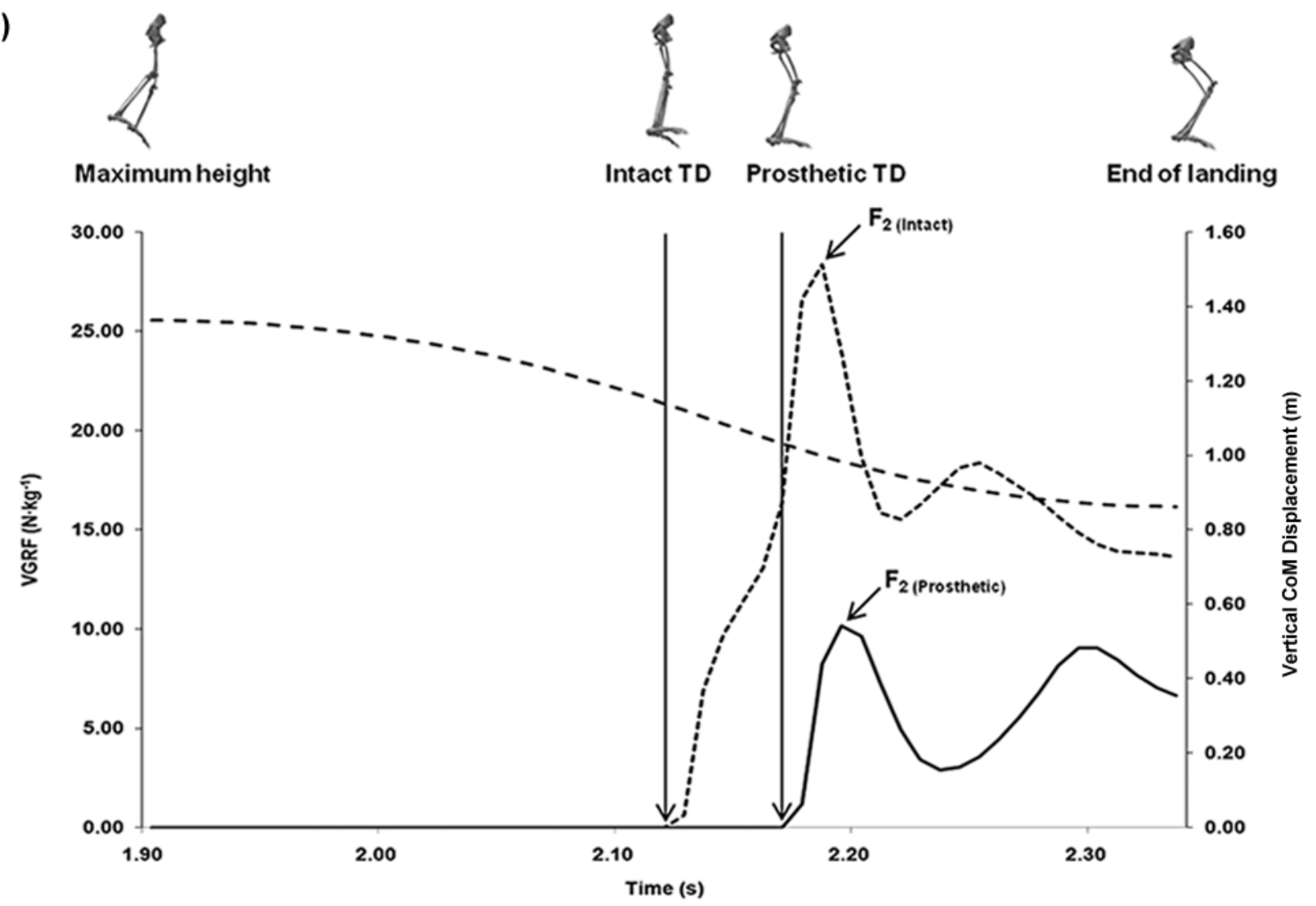

Figure 1.

Illustration of vertical ground reaction force (VGRF) and center of mass (CoM) during (a) whole countermovement jump and (b) zoomed into landing phase for TTA $\mathrm{T}_{3}$. Reported maximum peaks $\left(\mathrm{F}_{2}\right)$ are shown by downward arrows. Figure demonstrates largest delay in touchdown (TD) and asymmetrical loading between intact and prosthetic side for illustrative purposes. TTA = participant with transtibial amputation. 


\section{RESULTS}

The participants with TTA achieved FHs ranging from 0.09 to $0.24 \mathrm{~m}$ (Table 1 ). $\mathrm{F}_{2}$ magnitudes ranged from 18.49 to $29.95 \mathrm{~N} \cdot \mathrm{kg}^{-1}$ on the intact side and 4.42 to $26.19 \mathrm{~N} \cdot \mathrm{kg}^{-1}$ on the prosthetic side (Table 1). The FHs achieved by the participants with TTA were substantially lower $(p<0.001)$ than the heights achieved by the ND participants, although the peak force was similar. The TTA group intact magnitude was significantly larger $(p=$ 0.04 ) than the prosthetic magnitude, rejecting the hypothesis that the intact and prosthetic $F_{2}$ magnitudes would be symmetrical. Four participants with TTA displayed asymmetrical $\mathrm{F}_{2}$ magnitudes ( $\mathrm{SI}=51 \%-140 \%>\mathrm{ND}=$ $44 \%$ ) between their contralateral sides. Only $\mathrm{TTA}_{6}$ experienced a lower $\mathrm{F}_{2}$ on the intact side than on his prosthetic side. None of the participants with TTA contacted the ground simultaneously with both limbs, but they displayed a delay in TD onto their prosthetic limbs ranging from 0.01 to $0.08 \mathrm{~s}$ after TD onto the intact limb (Figure 1, Table 1). At the TTA group level, the duration from TD to $\mathrm{F}_{2}$ was significantly shorter $(p=0.03)$ on the prosthetic side than on the intact side, as seen in five participants with TTA (SI $=52 \%-157 \%>$ ND $=45 \%$ ).

The angle of the knee and hip at TD was similar to that seen for the ND participants. There was no statistically significant difference between the intact- and prosthetic-side group means for the ankle, knee, and hip angles at TD (Figure 2(a)). However, at the individual level, the SI was greater than ND participants (52\%) for five participants with TTA (SI $=100 \%-538 \%$ ) at the ankle. The prosthetic ankle was less plantar flexed than the ND ankle. At the knee, none of the participants with TTA displayed individual asymmetry (SI $=8 \%-43 \%<$ $\mathrm{ND}=44 \%)$. For the hip, only $\mathrm{TTA}_{2}(\mathrm{SI}=800 \%)$ was asymmetrical above the ND level (SI = 32\%).

The RoM on the intact side was similar to that of the ND participants. The TTA group had limited and significantly reduced ( $p=0.01)$ ankle RoM at the prosthetic side compared with the intact side. Five participants with TTA displayed individual asymmetry at the ankle RoMs $(\mathrm{SI}=147 \%-200 \%>\mathrm{ND}=134 \%)$ from TD to $\mathrm{F}_{2}$. The only participant with TTA to display symmetrical ankle RoMs $\left(\mathrm{TTA}_{5}\right)$ had a very small RoM at both ankles, a consequence of the dorsiflexed intact ankle at TD (Figure 2(b)). $\mathrm{TTA}_{4}$ displayed a prosthetic ankle RoM of $0^{\circ}$. At the group level, the participants with TTA displayed significantly reduced $(p=0.02)$ prosthetic-side knee RoM compared with the intact side, while three participants with TTA displayed individual asymmetry at the knee (SI $=140 \%-294 \%>$ ND = 134\%). The group RoM at the hip was not significantly different between the intact and prosthetic sides. However, at the individual level, $\mathrm{TTA}_{2-5}$ indicated higher SI values (67\%-145\%) than the ND participants (SI $=54 \%$ ).

The moments on the intact side were similar to those of the ND participants, while those on the prosthetic side were lower. The TTA group produced significantly reduced ( $p=0.03$ ) prosthetic ankle moments compared with the intact side (Figure 3(a)), despite $\mathrm{TTA}_{4}$ being the only participant with TTA to produce peak ankle moments that were outside the SI tolerance set by the ND participants (50\%). As a group, the participants with TTA also

Table 1.

Flight height (FH), touchdown (TD) delay, maximum peak $\left(\mathrm{F}_{2}\right)$ magnitude, and duration to $\mathrm{F}_{2}$.

\begin{tabular}{|c|c|c|c|c|c|c|c|c|}
\hline \multirow{2}{*}{ Outcome Measure } & \multicolumn{6}{|c|}{ Participant } & \multirow{2}{*}{ TTA (Mean \pm SD) } & \multirow{2}{*}{ ND $($ Mean \pm SD $)$} \\
\hline & TTA $_{1}$ & $\mathbf{T T A}_{2}$ & $\mathbf{T T A}_{3}$ & TTA $_{4}$ & TTA $_{5}$ & TTA $_{6}$ & & \\
\hline $\mathrm{FH}(\mathrm{m})$ & 0.24 & 0.19 & 0.17 & 0.13 & 0.10 & 0.09 & $0.15 \pm 0.06$ & $0.31 \pm 0.04$ \\
\hline CoM Displacement (m) & 0.09 & 0.10 & 0.10 & 0.14 & 0.06 & 0.09 & $0.10 \pm 0.03$ & $0.17 \pm 0.03$ \\
\hline $\mathrm{F}_{2(\mathrm{I})}\left(\mathrm{N} \cdot \mathrm{kg}^{-1}\right)$ & $20.24^{*}$ & 28.50 & $29.95^{*}$ & $25.06^{*}$ & $29.28^{*}$ & 18.49 & $25.25 \pm 4.89^{\dagger}$ & $22.34 \pm 9.69$ \\
\hline $\mathrm{F}_{2(\mathrm{P})}\left(\mathrm{N} \cdot \mathrm{kg}^{-1}\right)$ & 12.05 & 26.19 & 10.47 & 4.42 & 11.48 & 23.07 & $14.61 \pm 8.28$ & $19.60 \pm 6.69$ \\
\hline Duration to $\mathrm{F}_{2(\mathrm{I})}(\mathrm{s})$ & 0.05 & $0.08^{*}$ & $0.05^{*}$ & $0.08^{*}$ & 0.02 & $0.08^{*}$ & $0.06 \pm 0.02^{\dagger}$ & $0.07 \pm 0.02$ \\
\hline Duration to $\mathrm{F}_{2(\mathrm{P})}(\mathrm{s})$ & 0.03 & 0.04 & 0.01 & 0.01 & $0.04^{*}$ & 0.03 & $0.03 \pm 0.01$ & $0.07 \pm 0.02$ \\
\hline TD Delay (s) & 0.02 & 0.05 & 0.05 & 0.08 & 0.01 & 0.04 & $0.04 \pm 0.02$ & $0.01 \pm 0.00$ \\
\hline
\end{tabular}

*Indicates asymmetry above variable-specific ND mean \pm 1 SD Symmetry Index value and is placed on side with greater value.

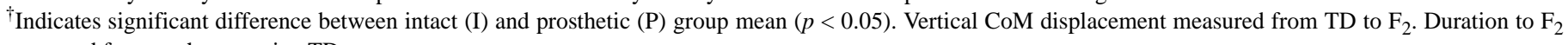
measured from each respective TD.

$\mathrm{CoM}=$ center of mass, $\mathrm{ND}=$ nondisabled, $\mathrm{SD}=$ standard deviation, $\mathrm{TTA}=$ participant with transtibial amputation . 

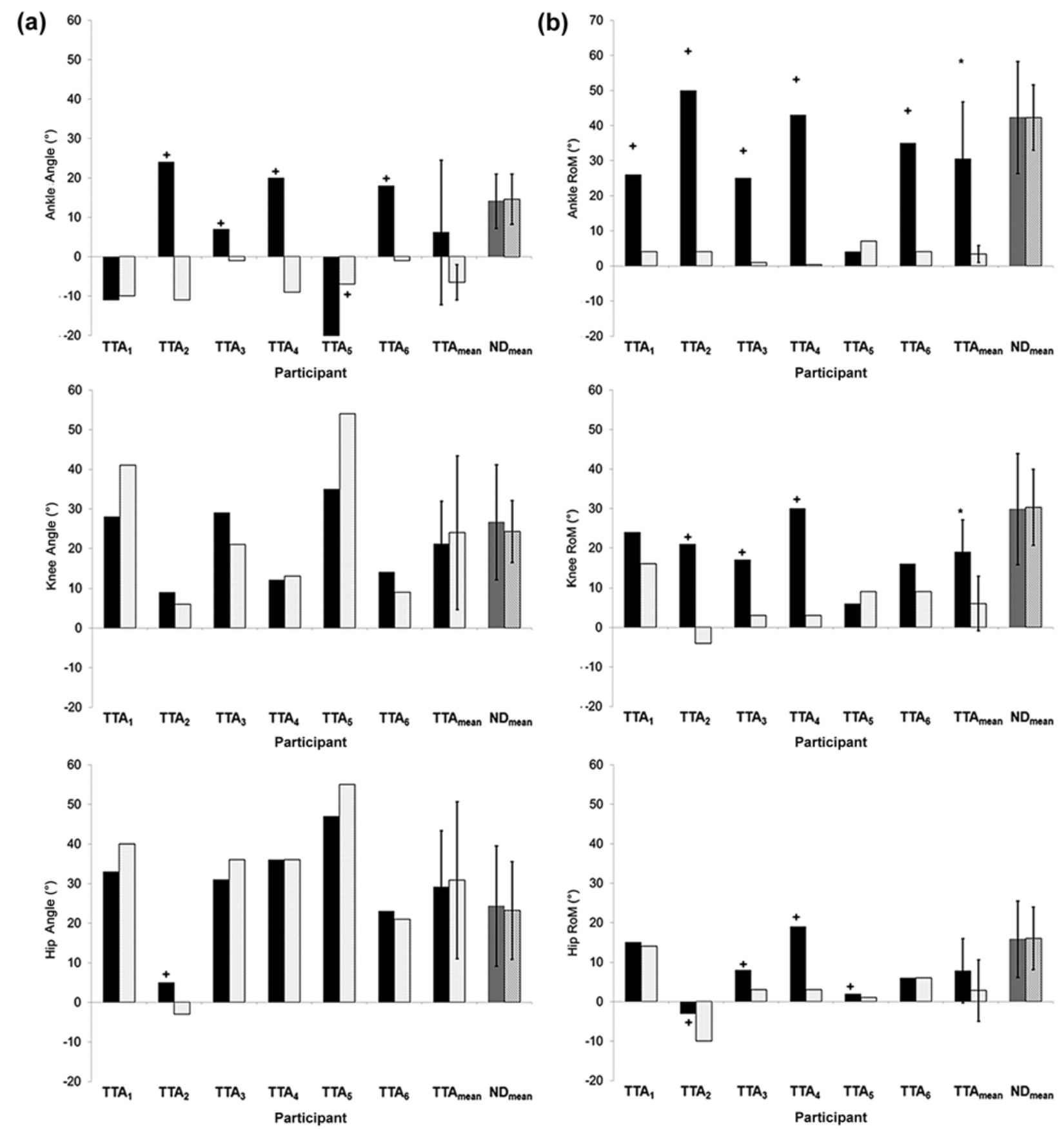

Figure 2.

Joint angles at (a) time of intact touchdown (TD) (dorsiflexion is negative) and (b) joint flexion range of motion (RoM) from respective TD to maximum peak. Plus symbol (+) indicates asymmetry above variable-specific nondisabled (ND) mean \pm 1 standard deviation Symmetry Index value. "Significant difference between intact and prosthetic group mean $(p<0.05)$. TTA = participant with transtibial amputation.

produced significantly reduced $(p>0.001)$ residual-limb knee moments compared with the intact side, which were asymmetrical for all (SI $=66 \%-179 \%>\mathrm{ND}=58 \%$ ) except $\mathrm{TTA}_{1}$ at the individual level. There was no statisti- cal difference between the intact and prosthetic hip extensor moments at the group level, although four participants with TTA indicated individual asymmetry at the hip (SI = $87 \%-132 \%>\mathrm{ND}=46 \%$ ). $\mathrm{TTA}_{1}$ and $\mathrm{TTA}_{6}$ were the only 
(a)
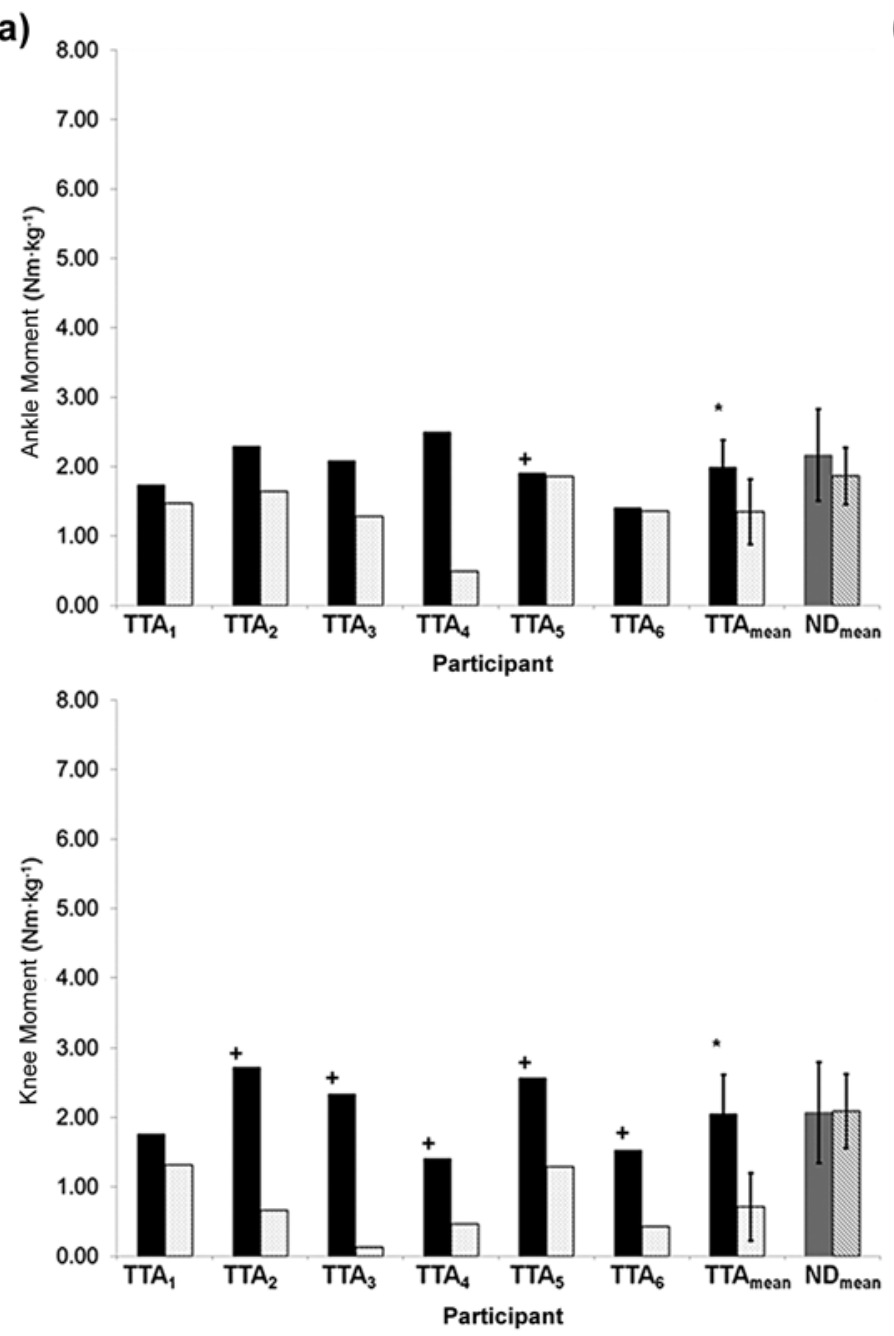

(b)
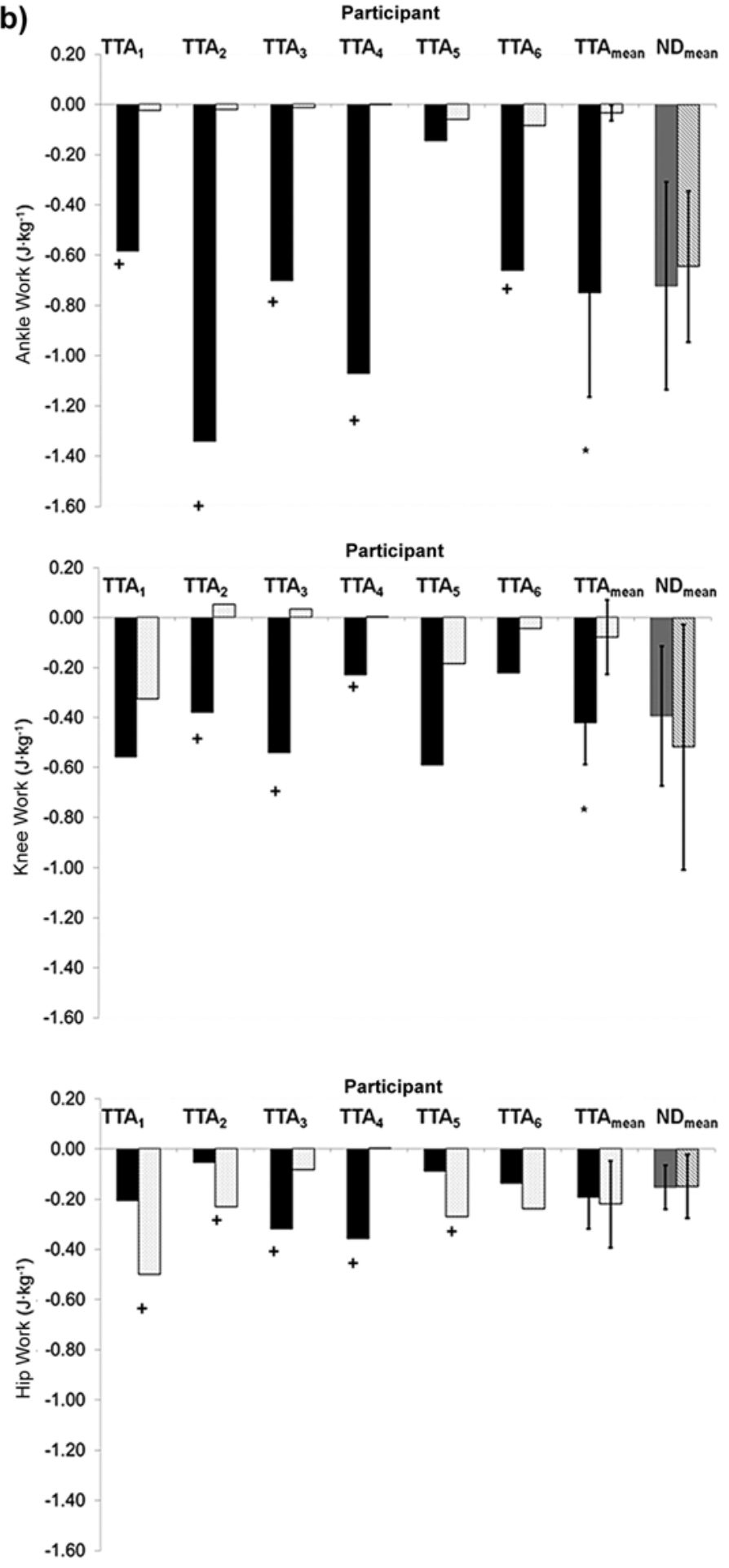

\section{Figure 3.}

(a) Peak extensor moments and (b) negative work done from touchdown to maximum peak to give insight into effort to control landing. Plus symbol (+) indicates asymmetry above variable-specific nondisabled (ND) mean \pm 1 standard deviation Symmetry Index value. ${ }^{*}$ Significant difference between intact and prosthetic group mean $(p<0.05)$. TTA = participant with transtibial amputation. 
participants to produce symmetrical, if slightly increased, extensor moments at the residual-limb hip compared with the intact side. The hypothesis that the intact and prosthetic joint moments would be symmetrical were therefore rejected for the ankle and knee, but accepted for the hip.

The participants with TTA produced significantly less $(p<0.001)$ negative work at the prosthetic ankle at the group level, while five participants with TTA displayed individual asymmetry in the work done at the ankle (SI = $155 \%-199 \%>\mathrm{ND}=95 \%$ ). $\mathrm{TTA}_{5}$ produced symmetrical work as a result of the relatively small work done on the intact side compared with the other participants with TTA on the intact side. Although the work being done by the participants with TTA as a group was significantly less $(p=0.01)$ at the residual-limb knee compared with the intact knee, the work done at the knee was asymmetrical for only three participants with TTA (SI $=202 \%-266 \%$ > $\mathrm{ND}=138 \%$ ) at the individual level. No significant difference in the work done at the hip was noted at the group level, despite $\mathrm{TTA}_{6}$ being the only participant to display symmetry between the intact and prosthetic side $\left(\mathrm{TTA}_{1-5}\right.$ $\mathrm{SI}=83 \%-204 \%>\mathrm{ND}=81 \%)$. The hypothesis that the intact and prosthetic joint work would be symmetrical was rejected for the ankle and knee, but accepted for the hip.

The normalized RMSD comparing TTA intact and prosthetic joint angles and moments were larger than that expected for ND participants in jumping over the time course from prosthetic TD to the end of landing, despite some participants with TTA being symmetrical in a number of discrete peak values (Table 2).

\section{DISCUSSION}

We investigated the asymmetry in the mechanisms used to accept the load on the lower limbs during a maxi- mal VJ landing in people with unilateral TTA to explore whether this movement was likely to promote musculoskeletal health or injury in recreationally active people with amputation. Even though increased peak loadings onto the intact limb have previously been reported in gait studies [20-21], it was unknown how the participants with TTA would contend with impact forces in a bilateral $\mathrm{VJ}$ that requires both ankles to act simultaneously as shock attenuators [8,30-31].

Symmetry is assumed in bilateral VJ landings and therefore seldom assessed or reported in the literature except when related to injury [32]. In order to determine the typical levels of symmetry in a bilateral landing, where the two limbs should theoretically contribute equally, considering the bilateral nature of the movement, we used ND participants to indicate asymmetry tolerance levels. In this study, some asymmetry was evident for the ND participants. However, for the participants with TTA, asymmetries were generally substantial with relatively low $F_{2}$ magnitudes on the prosthetic side and $\mathrm{F}_{2}$ magnitudes comparable with those of the ND participants on the intact side. While it is not possible to directly compare the $\mathrm{F}_{2}$ magnitudes with the literature because of the substantially reduced heights from which the participants with TTA landed, we noted that the participants with TTA experienced similar $F_{2}$ magnitudes on the intact side compared with ND jumpers in literature performing drop landings from $0.30 \mathrm{~m}$ [9,33-34], despite landing from heights of only $0.15 \pm 0.06 \mathrm{~m}$. These reduced FHs, compared with ND participants in literature [35-36], are consistent with a previous study using recreationally active people with amputation [19] and may be related to their reduced capacity to produce the required mechanisms to propel the body into flight [18].

We examined the mechanisms and asymmetry that underpin the absorption of $\mathrm{F}_{2}$ to control the landing from

Table 2.

Normalized root mean square difference (RMSD) between intact and prosthetic sides for joint angle and moment in loading phase.

\begin{tabular}{|c|c|c|c|c|c|c|c|c|}
\hline \multirow{2}{*}{ Variable } & \multicolumn{6}{|c|}{ Participant } & \multirow{2}{*}{ TTA $($ Mean \pm SD) } & \multirow{2}{*}{ ND $($ Mean \pm SD $)$} \\
\hline & TTA $_{1}$ & TTA $_{2}$ & TTA $_{3}$ & TTA $_{4}$ & TTA $_{5}$ & TTA $_{6}$ & & \\
\hline Ankle Angle $\left(^{\circ}\right)$ & $76.0^{*}$ & $6.7^{*}$ & $14.3^{*}$ & $17.9^{*}$ & $15.2^{*}$ & $22.6^{*}$ & $27.8 \pm 25.3$ & $1.0 \pm 0.7$ \\
\hline Hip Angle $\left(^{\circ}\right)$ & $23.3^{*}$ & $13.3^{*}$ & $5.0^{*}$ & $4.5^{*}$ & $3.8^{*}$ & $4.7^{*}$ & $10.9 \pm 9.5$ & $1.1 \pm 0.6$ \\
\hline Ankle Moment $\left(^{\circ}\right)$ & $20.4^{*}$ & $21.9^{*}$ & $14.9^{*}$ & $14.1^{*}$ & $9.1^{*}$ & $12.3^{*}$ & $12.6 \pm 5.3$ & $1.8 \pm 1.2$ \\
\hline Knee Moment $\left(^{\circ}\right)$ & $21.2^{*}$ & $11.2^{*}$ & $15.0^{*}$ & $13.4^{*}$ & $9.8^{*}$ & $10.8^{*}$ & $9.6 \pm 2.9$ & $1.9 \pm 0.7$ \\
\hline
\end{tabular}

${ }^{*}$ Indicates normalized RMSD above variable-specific ND mean \pm 1 SD.

$\mathrm{ND}=$ nondisabled, $\mathrm{SD}=$ standard deviation, TTA = participant with transtibial amputation. 
a maximal VJ. The reduction of the downward momentum to zero is related to impulse (force $\times$ time over which the force acts). The peak force magnitudes experienced by jumpers are affected by the mechanism of the joints (soft, normal, or stiff) in landing [34], while the time to $\mathrm{F}_{2}$ is influenced by the kinematic conditions at TD and joint actions to control the downward momentum. While the magnitudes of $\mathrm{F}_{2}$ were mostly asymmetrical, the timing at which it occurred was almost simultaneous, despite a significantly delayed TD on the prosthetic side. This delay between the intact- and prosthetic-side TD essentially caused the participants with TTA to perform a unilateral landing onto the intact limb until the prostheticside limb also reached TD and bilateral contact with the ground was established. At TD, all participants with TTA except $\mathrm{TTA}_{1}$ displayed individual asymmetry at the ankle, primarily due to the difference between the plantar-flexed intact ankle and prosthetic ankle, which is not able to actively plantar flex. The quasi-unilateral landing onto the intact limb contributed to the larger $\mathrm{F}_{2}$ magnitudes on the intact side. $\mathrm{TTA}_{1}$ and $\mathrm{TTA}_{5}$, who were dorsiflexed at the intact ankle at the time of TD, employed a limb-shortening mechanism through increased residuallimb knee and hip flexion at the time of intact TD. This also caused a delay in contact onto the prosthetic limb, pointing to an active avoidance to load the prosthetic limb in the initial part of landing leading up to $F_{2}$. This, in combination with the participants with TTA's reluctance to experience symmetrical peak loadings, may potentially point to an anticipation and subsequent avoidance (based on experience) of high loadings onto the residual limb during a dynamic movement. The two participants with TTA who were only 1 yr postamputation (TTA $_{2}$ and $\mathrm{TTA}_{6}$, Table 3) presented with the lowest asymmetry in $F_{2}$ magnitudes, possibly because they had the most recent exposure to rehabilitation, which often emphasizes the goal of attaining symmetry. They also only had $1 \mathrm{yr}$ to adapt and favor the intact limb for accommodating impact forces compared with the other participants with TTA [21].

Consequent to the simultaneous occurrence of $\mathrm{F}_{2}$, despite the temporal differences in TD between the intact and prosthetic limbs, there were significant differences in the duration from TD to $\mathrm{F}_{2}$ between the intact and prosthetic sides, as well as the prosthetic side compared with the ND participants. On the intact side, the participants with TTA generally reached $F_{2}$ at durations from TD similar to those reported in the literature [12,37-38], while the majority reached $\mathrm{F}_{2}$ in less time on the prosthetic side, most likely as a result of the reduced prosthetic ankle RoM and absent plantar flexors to contract eccentrically [12]. The implied increase in rate of loading may potentially contribute to skin breakdown if jumping repeatedly and should be taken into consideration by healthcare professionals when advising people with amputation to engage in recreational sport.

In general, the participants with TTA were mostly symmetrical at the knee and hip angles at TD, while those presenting with the greatest intact plantar flexion at TD landed with a more extended residual-limb knee, most likely in an attempt to maintain stability at that joint [39-40] and postural control by keeping the CoM over the base of support [41]. However, this strategy may expose them to anterior cruciate ligament injury, since the hamstring muscles are less able to prevent tibial translation with the knee closer to extension [42]. If the prosthetic socket were to limit anterior translation of the proximal tibia, residual-limb skin breakdown due to pressures applied by the socket [14] is likely to arise if repetitive jumping were to occur.

Table 3.

Participant characteristics.

\begin{tabular}{|c|c|c|c|c|c|c|c|}
\hline Participant & Sex & Age (yr) & Height (m) & Mass (kg) & $\begin{array}{c}\text { Side of } \\
\text { Amputation }\end{array}$ & Prosthesis & $\begin{array}{c}\text { Time Since } \\
\text { Amputation (yr) }\end{array}$ \\
\hline $\mathrm{TTA}_{1}$ & $\mathrm{M}$ & 39 & 1.82 & 83 & $\mathrm{~L}$ & Vari-Flex & 21 \\
\hline $\mathrm{TTA}_{3}$ & M & 38 & 1.88 & 70 & $\mathrm{R}$ & Modullar III & 9 \\
\hline $\mathrm{TTA}_{4}$ & $\mathrm{~F}$ & 33 & 1.79 & 100 & $\mathrm{R}$ & Mobis 1D10 & 7 \\
\hline
\end{tabular}


Downward momentum of the CoM is slowed through increased joint flexion coupled with extensor moments to prevent collapse of the joint. Eccentric work done at the joints indicates the contribution of the various muscle groups to the total reduction of momentum. For the participants with TTA as a group, both the joint flexion to $\mathrm{F}_{2}$ (RoM) and moments were reduced on the prosthetic side, indicating its lack of involvement in controlling the landing. Reduced proprioceptive feedback due to the amputation may have prevented the generation of adequate afferent stimuli to organize an appropriate response to the VGRF perturbation in the short time from TD to $F_{2}$ [43]. Compared with the prosthetic side, significantly larger RoM and extensor moments were noted on the intact side for the participants with TTA as a group to accommodate the large peak forces resulting from the pseudounilateral landing onto the intact limb. Although the peak ankle moments were mostly symmetrical for the participants with TTA at the individual level, work done at the ankles was asymmetrical, with more work absorbed at the intact side, indicating the dissipation of energy through this joint. The carbon fiber used to fabricate the prosthetic toe spring is compliant when loaded, yet offers resistance during loading to provide stability to the prosthetic structure. These physical properties of carbon fiber mimic eccentric muscle contraction of the plantar flexors, which prevent collapse of the ankle joint and are most likely the source of the negative work done at the prosthetic ankles during landing. The absence of prosthetic ankle work generation by $\mathrm{TTA}_{4}$ resulted from the type of prosthesis worn.

Significantly reduced extensor moments at the residuallimb knee indicate an attempt by the participants with TTA as a group to reduce loading about this joint, similar to people with amputation stepping down from stairs [44]. The asymmetrical effort to control the landing was also evident in the significantly reduced work contributions by the residual-limb knee compared with the intact knee. Increased negative work at the residual-limb hip by the majority of participants with TTA indicates that the hip was the main contributing source on the prosthetic side to control the landing, which is in agreement with the literature [34].

To determine the overall symmetry of the movement over the landing period, we assessed the RMSD at each time instant from TD to the end of landing. While some participants with TTA indicated symmetry in some of the discrete peak values, over the phase as a whole, all partici- pants with TTA were asymmetrical (Table 2), implying a greater risk of injuries due to asymmetries.

On an individual level, $\mathrm{TTA}_{5}$ landed with a high $\mathrm{F}_{2}$ from a relatively low $\mathrm{FH}$ of $0.10 \mathrm{~m}$ and a short duration to $\mathrm{F}_{2}$ on the intact side, resulting from landing in a very stiff manner with little joint RoM on both sides. Consequently, little work was done at the intact ankle, indicating a poor landing strategy. Looking at $\mathrm{TTA}_{1}$, it seemed that this participant employed an effective strategy to accommodate the downward momentum, resulting in relatively small $F_{2}$ magnitudes despite landing from the greatest height and vertical velocity compared with the other participants with TTA. TTA 1 touched down with the intact ankle in dorsiflexion, symmetrical to the prosthetic ankle. Large RoMs and moments at the residual-limb knee and hip compensated for the reduced work resulting from the small RoM at the ankles. The results for $\mathrm{TTA}_{1}$, in comparison with the other participants with TTA, raise the question whether they could be taught to employ this landing strategy to better accommodate impact forces, especially since it has been shown that extrinsic feedback can significantly decrease VGRF [45] and the implied injury potential during landing.

We chose not to control for landing height by assessing a drop landing, because preliminary work demonstrated that people with amputation have difficulty performing drop jumps because of the limited prosthetic ankle mobility inhibiting stepping down mechanics. This, combined with a lack of research on jump landing mechanics with amputation and knowledge on safe landing heights, drove the selection of countermovement VJ landings. Despite the similarities in jumping exposure through recreational activities between the TTA and ND participants, a direct comparison of the results with the ND participants should be completed with caution because the landing heights differed significantly $(p<0.001)$ between these two groups. Within the parameters and limitations of our study, we found that the participants with TTA experienced peak landing forces that were similar to those experienced by ND participants even though the participants with TTA landed from lower FHs. Limitations of the study included the small number of participants with TTA who qualified to partake in this study based on the inclusion criteria and our inability to control for the prostheses and -2shoes worn by the participants with TTA. Due to the small number of participants with TTA, the results should be generalized with caution, although the value of the research is not compromised. 


\section{CONCLUSIONS}

Although the exact force threshold where injury may occur is still unknown, the higher forces and moments experienced on the intact side indicate that jump landings may potentially lead to injury or progressive joint degeneration when taking into consideration that people with TTA are predisposed to OA at the intact knee and hip [38]. The $F_{2}$ peaks occurred almost simultaneously, despite a delay in TD on the prosthetic side. From an injury perspective, the integrity of all biological material is subject not only to the magnitude of an external perturbation, but also the time in which it is applied [9]. Therefore, the shorter durations to $F_{2}$ due to limited prosthetic ankle RoM and absent plantar flexors [12] may potentially increase the risk for injury and skin breakdown on the prosthetic side. The participants with TTA reduced the peak force magnitude onto the prosthetic side, which was likely a strategy to minimize this injury risk. Symmetry in jumping is usually required to avoid excessive loading onto one or the other limb. However, for people with amputation it is not advised to load symmetrically since the mechanical constraints of the prosthesis will cause large forces on the prosthetic side. The level of asymmetry and the mechanism adopted by people with amputation to control momentum does not necessarily seem to be related to the prosthesis. The participants with TTA wearing more dynamic prostheses did not necessarily perform any differently than those with more inert prostheses, both of which presented quite different landing mechanics compared with ND jumpers. This suggests that prostheses may be insufficient to compensate for the loss of the ankle joint's anatomical structure. Although physical activity promotes physiological and psychological health, and jumping carries great potential to stimulate osteogenesis through mechanical loading, both the intact and prosthetic limbs seem to be at risk for potential injury during landing. Further research is required to explore the pathomechanics and biomechanical interaction between people with amputation and lower-leg prostheses in jump landings. An understanding of the maximal capacity to control the momentum in landing will inform correct landing techniques, rehabilitation guidelines, and possible prosthetic design interventions aimed toward the safety of people with amputation engaging in recreational sport involving jumping.

\section{ACKNOWLEDGMENTS}

\section{Author Contributions:}

Study concept and design: M. Schoeman, S. C. Strike, C. E. Diss. Acquisition of data: M. Schoeman.

Analysis and interpretation of data: M. Schoeman, S. C. Strike, C. E. Diss.

Drafting of manuscript: M. Schoeman.

Critical revision of manuscript for important intellectual content:

M. Schoeman, S. C. Strike, C. E. Diss.

Statistical analysis: M. Schoeman, S. C. Strike, C. E. Diss.

Study supervision: S. C. Strike, C. E. Diss.

Financial Disclosures: The authors have declared that no competing interests exist.

Funding/Support: This material was unfunded at the time of manuscript preparation.

Additional Contributions: We would like to thank all the participants involved in this study for their willingness, time, and cooperation. Institutional Review: Prior to data collection, participants gave written informed consent. A detailed proposal of this study was evaluated and approved by the University of Roehampton's Ethics Committee, as well as the United Kingdom National Health Services' Research Ethics Committee.

Participant Follow-Up: The authors do not plan to inform participants of the publication of this study due to a lack of contact information.

\section{REFERENCES}

1. Sousa AI, Corredeira R, Pereira AL. The body in persons with an amputation. Adapt Phys Activ Q. 2009;26(3):236-58. [PMID:19799096]

2. Warburton DE, Nicol CW, Bredin SS. Health benefits of physical activity: the evidence. CMAJ. 2006;174(6):801-9. [PMID:16534088]

3. Bauer JJ, Fuchs RK, Smith GA, Snow CM. Quantifying force magnitude and loading rate from drop landings that induce osteogenesis. J Appl Biomech. 2001;17:142-52.

4. Dufek JS, Bates BT. Biomechanical factors associated with injury during landing in jump sports. Sports Med. 1991; 12(5):326-37. [PMID:1763250] http://dx.doi.org/10.2165/00007256-199112050-00005

5. Vignon E, Valat JP, Rossignol M, Avouac B, Rozenberg S, Thoumie P, Avouac J, Nordin M, Hilliquin P. Osteoarthritis of the knee and hip and activity: A systematic international review and synthesis (OASIS). Joint Bone Spine. 2006; 73(4):442-55. [PMID:16777458]

http://dx.doi.org/10.1016/j.jbspin.2006.03.001

6. Bosco C, Komi PV. Potentiation of the mechanical behavior of the human skeletal muscle through prestretching. Acta Physiol Scand. 1979;106(4):467-72. [PMID:495154] http://dx.doi.org/10.1111/j.1748-1716.1979.tb06427.x

7. Bisseling RW, Hof AL. Handling of impact forces in inverse dynamics. J Biomech. 2006;39(13):2438-44. 


\section{[PMID:16209869]}

http://dx.doi.org/10.1016/j.jbiomech.2005.07.021

8. Gross TS, Nelson RC. The shock attenuation role of the ankle during landing from a vertical jump. Med Sci Sports Exerc. 1988;20(5):506-14. [PMID:3193868] http://dx.doi.org/10.1249/00005768-198810000-00013

9. Fowler NE, Lees A. A comparison of the kinetic and kinematic characteristics of plyometric drop-jump and pendulum exercises. J Appl Biomech. 1998;14:260-75.

10. Lees A. Methods of impact absorption when landing from a jump. Eng Med. 1981;10(4):207-11. http://dx.doi.org/10.1243/EMED_JOUR_1981_010_055_02

11. Liebermann DG, Hoffman JR. Timing of preparatory landing responses as a function of availability of optic flow information. J Electromyogr Kinesiol. 2005;15(1):120-30. [PMID:15642660]

http://dx.doi.org/10.1016/j.jelekin.2004.07.005

12. Abián-Vicén J, Alegre LM, Fernández-Rodríguez JM, Lara AJ, Meana M, Aguado X. Ankle taping does not impair performance in jump or balance tests. J Sports Sci Med. 2008;7(3):350-56. [PMID:24149902]

13. Dufek JS, Bates BT. The evaluation and prediction of impact forces during landings. Med Sci Sports Exerc. 1990;22(3):370-77. [PMID:2381305] http://dx.doi.org/10.1249/00005768-199006000-00014

14. Dudek NL, Marks MB, Marshall SC, Chardon JP. Dermatologic conditions associated with use of a lower-extremity prosthesis. Arch Phys Med Rehabil. 2005;86(4):659-63. [PMID:15827914] http://dx.doi.org/10.1016/j.apmr.2004.09.003

15. Lequesne MG, Dang N, Lane NE. Sport practice and osteoarthritis of the limbs. Osteoarthritis Cartilage. 1997; 5(2):75-86. [PMID:9135819] http://dx.doi.org/10.1016/S1063-4584(97)80001-5

16. Nigg BM, Bobbert $M$. On the potential of various approaches in load analysis to reduce the frequency of sports injuries. J Biomech. 1990;23(Suppl 1):3-12.

[PMID:2081742] http://dx.doi.org/10.1016/0021-9290(90)90036-3

17. Nolan L, Lees A. Touch-down and take-off characteristics of the long jump performance of world level above- and below-knee amputee athletes. Ergonomics. 2000;43(10): 1637-50. [PMID:11083143] http://dx.doi.org/10.1080/001401300750004050

18. Schoeman M, Diss CE, Strike SC. Kinetic and kinematic compensations in amputee vertical jumping. J Appl Biomech. 2012;28(4):438-47. [PMID:22086122]

19. Strike SC, Diss C. The biomechanics of one-footed vertical jump performance in unilateral trans-tibial amputees. Prosthet Orthot Int. 2005;29(1):39-51. [PMID:16180376] http://dx.doi.org/10.1080/17461550500069596
20. Engsberg JR, Lee AG, Patterson JL, Harder JA. External loading comparisons between able-bodied and below-kneeamputee children during walking. Arch Phys Med Rehabil. 1991;72(9):657-61. [PMID:1859261]

21. Nolan L, Lees A. The functional demands on the intact limb during walking for active trans-femoral and transtibial amputees. Prosthet Orthot Int. 2000;24(2):117-25.

[PMID:11061198]

http://dx.doi.org/10.1080/03093640008726534

22. Royer T, Koenig M. Joint loading and bone mineral density in persons with unilateral, trans-tibial amputation. Clin Biomech (Bristol, Avon). 2005;20(10):1119-25. [PMID:16139403] http://dx.doi.org/10.1016/j.clinbiomech.2005.07.003

23. Hara M, Shibayama A, Takeshita D, Fukashiro S. The effect of arm swing on lower extremities in vertical jumping. J Biomech. 2006;39(13):2503-11. [PMID:16168998] http://dx.doi.org/10.1016/j.jbiomech.2005.07.030

24. Davis RB, Õunpuu S, Tyburski D, Gage JR. A gait analysis data collection and reduction technique. Hum Mov Sci. 1991;10(5):575-87. http://dx.doi.org/10.1016/0167-9457(91)90046-Z

25. Miller DI. Resultant lower extremity joint moments in below-knee amputees during running stance. J Biomech. 1987;20(5):529-41. [PMID:3611127] http://dx.doi.org/10.1016/0021-9290(87)90253-3

26. Winter DA. The biomechanics and motor control of human gait: Normal, elderly and pathological. Waterloo (Canada): University of Waterloo Press; 1991.

27. Woltring HJ. A Fortran package for generalized, crossvalidatory spline smoothing and differentiation. Adv Eng Softw. 1986;8(2):104-13. http://dx.doi.org/10.1016/0141-1195(86)90098-7

28. Flanagan SP, Salem GJ. Bilateral differences in the net joint torques during the squat exercise. J Strength Cond Res. 2007;21(4):1220-26. [PMID:18076249]

29. Giakas G, Baltzopoulos V. Time and frequency domain analysis of ground reaction forces during walking: an investigation of variability and symmetry. Gait Posture. 1997;5(3):189-97. http://dx.doi.org/10.1016/S0966-6362(96)01083-1

30. Devita P, Skelly WA. Effect of landing stiffness on joint kinetics and energetics in the lower extremity. Med Sci Sports Exerc. 1992;24(1):108-15. [PMID:1548984] http://dx.doi.org/10.1249/00005768-199201000-00018

31. Malliaras P, Cook JL, Kent P. Reduced ankle dorsiflexion range may increase the risk of patellar tendon injury among volleyball players. J Sci Med Sport. 2006;9(4):304-9. [PMID:16672192]

32. Paterno MV, Ford KR, Myer GD, Heyl R, Hewett TE. Limb asymmetries in landing and jumping 2 years following anterior cruciate ligament reconstruction. Clin J Sport 
Med. 2007;17(4):258-62. [PMID:17620778]

http://dx.doi.org/10.1097/JSM.0b013e31804c77ea

33. DiStefano LJ, Padua DA, Brown CN, Guskiewicz KM. Lower extremity kinematics and ground reaction forces after prophylactic lace-up ankle bracing. J Athl Train. 2008; 43(3):234-41. [PMID:18523572]

34. Zhang SN, Bates BT, Dufek JS. Contributions of lower extremity joints to energy dissipation during landings. Med Sci Sports Exerc. 2000;32(4):812-19. [PMID:10776901] http://dx.doi.org/10.1097/00005768-200004000-00014

35. Moran KA, Wallace ES. Eccentric loading and range of knee joint motion effects on performance enhancement in vertical jumping. Hum Mov Sci. 2007;26(6):824-40.

[PMID:17928080] http://dx.doi.org/10.1016/j.humov.2007.05.001

36. Vanrenterghem J, Lees A, Lenoir M, Aerts P, De Clercq D. Performing the vertical jump: Movement adaptations for submaximal jumping. Hum Mov Sci. 2004;22(6):713-27. [PMID:15063050] http://dx.doi.org/10.1016/j.humov.2003.11.001

37. Bennett DR, Blackburn JT, Boling MC, McGrath M, Walusz H, Padua DA. The relationship between anterior tibial shear force during a jump landing task and quadriceps and hamstring strength. Clin Biomech (Bristol, Avon). 2008;23(9):1165-71. [PMID:18599168] http://dx.doi.org/10.1016/j.clinbiomech.2008.05.005

38. Melzer I, Yekutiel M, Sukenik S. Comparative study of osteoarthritis of the contralateral knee joint of male amputees who do and do not play volleyball. J Rheumatol. 2001; 28(1):169-72. [PMID:11196520]

39. Engsberg JR, Lee AG, Tedford KG, Harder JA. Normative ground reaction force data for able-bodied and below-kneeamputee children during walking. J Pediatr Orthop. 1993; 13(2):169-73. [PMID:8459005]

40. Sanderson DJ, Martin PE. Lower extremity kinematic and kinetic adaptations in unilateral below-knee amputees during walking. Gait Posture. 1997;6(2):126-36. http://dx.doi.org/10.1016/S0966-6362(97)01112-0
41. Cortes N, Onate J, Abrantes J, Gagen L, Dowling E, Van Lunen B. Effects of gender and foot-landing techniques on lower extremity kinematics during drop-jump landings. J Appl Biomech. 2007;23(4):289-99. [PMID:18089927]

42. Fagenbaum R, Darling WG. Jump landing strategies in male and female college athletes and the implications of such strategies for anterior cruciate ligament injury. Am J Sports Med. 2003;31(2):233-40. [PMID:12642258]

43. Enoka RM. Neuromechanical basis of kinesiology. Champaign (IL): Human Kinetics; 1994.

44. Jones SF, Twigg PC, Scally AJ, Buckley JG. The mechanics of landing when stepping down in unilateral lower-limb amputees. Clin Biomech (Bristol, Avon). 2006;21(2):184-93. [PMID:16274904] http://dx.doi.org/10.1016/j.clinbiomech.2005.09.015

45. Cronin JB, Bressel E, Fkinn L. Augmented feedback reduces ground reaction forces in the landing phase of the volleyball spike jump. J Sport Rehabil. 2008;17(2):148-59. [PMID:18515914]

Submitted for publication October 29, 2012. Accepted in revised form June 13, 2013.

This article and any supplementary material should be cited as follows:

Schoeman M, Diss CE, Strike SC. Asymmetrical loading demands associated with vertical jump landings in people with unilateral transtibial amputation. J Rehabil Res Dev. 2013;50(10):1435-48.

http://dx.doi.org/10.1682/JRRD.2012.10.0199

ResearcherID/ORCID: Marlene Schoeman, PhD: G-41122011

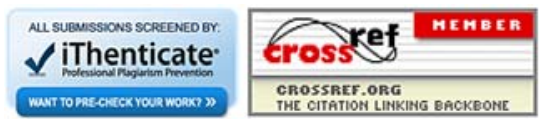

